\title{
Detection and quantification of Salmonella in fresh vegetables in Perak, Malaysia
}

\author{
${ }^{1}$ Saw, S.H., ${ }^{2}$ Mak, J.L., ${ }^{2}$ Tan, M.H., ${ }^{2}$ Teo, S.T., ${ }^{1}$ Tan, T.Y., ${ }^{1}$ Cheow, M.Y.K., ${ }^{2}$ Ong, C.A., \\ ${ }^{1}$ Chen, S.N., ${ }^{3}$ Yeo, S.K., ${ }^{4}$ Kuan, C.S., ${ }^{5,6}$ Son, R., ${ }^{5}$ New, C.Y., ${ }^{2}$ Phuah, E.T., ${ }^{5}$ Thung, T.Y. \\ and ${ }^{3 *}$ Kuan, C.H. \\ ${ }^{1}$ Department of Allied Health Sciences, Faculty of Science, Universiti Tunku Abdul Rahman, 31900 \\ Kampar, Perak, Malaysia \\ ${ }^{2}$ Department of Agricultural and Food Science, Faculty of Science, Universiti Tunku Abdul Rahman \\ (UTAR), 31900 Kampar, Perak, Malaysia \\ ${ }^{3}$ School of Biosciences, Taylor's University Lakeside Campus, 47500 Subang Jaya, Selangor, Malaysia \\ ${ }^{4}$ Neogenix Laboratoire Sdn Bhd, C707, Level 7, Block C, Kelana Square, Kelana Jaya, 47301, Petaling \\ Jaya, Selangor, Malaysia \\ ${ }^{5}$ Department of Food Science, Faculty of Food Science and Technology, Universiti Putra Malaysia, 43400 \\ Serdang, Selangor, Malaysia \\ ${ }^{6}$ Food Safety and Food Integrity, Institute of Tropical Agriculture and Food Security, Universiti Putra \\ Malaysia, 43400 Serdang, Selangor, Malaysia
}

\begin{abstract}
Article history:
Received: 19 September 2019

Received in revised form: 16

October 2019

Accepted: 19 October 2019

Available Online: 27 October 2019
\end{abstract}

Keywords:

S. enterica serovar

Enteritidis,

S. enterica serovar

Typhimurium,

Vegetables,

Prevalence,

Multiplex PCR

DOI:

https://doi.org/10.26656/fr.2017.4(2).316

\begin{abstract}
The eating of fresh and minimally processed vegetables is getting popular among Malaysians. This trend poses an increased risk of food poisoning associated with the consumption of fresh produce contaminated with pathogenic bacteria. Salmonellosis is a foodborne disease caused by several non-typhoidal Salmonella enterica serovars, predominantly serovars Enteritidis and Typhimurium. The present study aimed to determine the prevalence of Salmonella spp., S. enterica serovar Enteritidis and $S$. enterica serovar Typhimurium in fresh leafy vegetables such as cabbages $(\mathrm{n}=40)$, lettuces $(n=20)$, and fruit vegetables such as tomatoes $(n=40)$, carrots $(n=40)$ and cucumbers $(\mathrm{n}=40)$, which were sold by three different hypermarkets and a wet market in Kampar, Perak, Malaysia. The study was performed over a period of 13 months (January 2018 to January 2019). A combination of most probable number-multiplex polymerase chain reaction (MPN-mPCR) method was used to quantify the concentrations of Salmonella spp., S. enterica serovar Enteritidis and S. enterica serovar Typhimurium in the examined samples. The results of this study demonstrated that of the vegetables tested, tomatoes, carrots and lettuces were not contaminated by Salmonella spp., S. enterica serovar Enteritidis and S. enterica serovar Typhimurium. However, the presence of Salmonella spp. was detected in 3.3\% of cabbages from the hypermarket, with estimated microbial loads ranging from $<3.0 \mathrm{MPN} / \mathrm{g}$ to $15.0 \mathrm{MPN} / \mathrm{g}$. On the other hand, S. enterica serovar Typhimurium was detected in $10.0 \%$ of the cucumbers from hypermarkets and $20 \%$ of them from the wet market. Their microbial loads were ranging from $<3.0 \mathrm{MPN} / \mathrm{g}$ to $>1,100 \mathrm{MPN} / \mathrm{g}$. This indicated that cabbages and cucumbers could be the potential sources of salmonellosis. Therefore, the monitoring of food safety and hygienic practices should be strictly enforced by relevant government agencies to avoid potential poisoning by foodborne pathogens.
\end{abstract}

\section{Introduction}

Salmonella is a Gram-negative rod-shaped bacterium which is responsible for causing salmonellosis in humans. In the United States, 1.2 million illnesses, 23,000 hospitalizations and 450 deaths cases caused by
Salmonella were reported every year (CDC, 2019b). Most of the individuals infected with Salmonella develop diarrhoea, fever and abdominal cramps within 12 to 72 hrs. Vulnerable groups such as children, older people and immune-compromised individuals may experience 
severe dehydration which could be life-threatening when infected with Salmonella (WHO, 2018).

Among the 2,659 serovars of Salmonella, S. enterica serovar Enteritidis and $S$. enterica serovar Typhimurium is the most common foodborne pathogens in the developed countries (Hendriksen et al., 2011). Generally, Salmonella poisonings are mostly found to be associated with the consumption of contaminated bovine or chicken products, as these pathogens have been reported to reside in the intestine of these animals (Najwa et al., 2015). Nevertheless, Salmonella poisonings had also been reported after consuming ready-to-eat (RTE) vegetables such as bean sprouts, lettuces, tomatoes, carrots, alfalfa sprouts, Asiatic pennyworts, water dropworts, cabbages and cucumbers (Bordini et al., 2007; Centre For Food Safety, 2014; Najwa et al., 2015; Kuan et al., 2017). In 2004, salmonellosis outbreak had occurred in the UK, involving 350 people who had consumed lettuces in fastfood restaurants; following an outbreak of $S$. Typhimurium in the US two years after the incident, resulting in 183 individuals fallen sick after eating the contaminated tomatoes (Von Haaren, 2004; CDC, 2006). Salmonella food poisoning was also reported in Australia involving 92 individuals who had consumed contaminated pre-packed lettuces (Suzanne, 2016). Thus, the presence of Salmonella in RTE vegetables should not be taken lightly globally.

In Malaysia, the exact number of incidences of foodborne illnesses associated with the consumption of fresh produce remains unknown as there has been little attempt to address this problem (Kuan et al., 2017). However, a salmonellosis outbreak involving 171 individuals and mortality after the consumption of RTE vegetables was reported in Kelantan in 2005 (Tunung et al., 2007). Malaysians pose a higher risk in salmonellosis as they have become more health-conscious and consume more vegetables especially cabbage (Brassica oleracea var. capitata), celery (Apium graveolens), spinach (Spinacia oleracea), carrot (Daucus carota), cauliflower (Brassica oleracea var. cauliflora), tomato (Lycopersicum esculentum), cucumber (Cucumis sativus) and long bean (Vigna sesquipedalis) (Nurul Izzah et al., 2012). Hence, more prevalence studies on Salmonella in vegetables are needed to create awareness about the safety and quality of the vegetables.

This study aimed to detect the presence of Salmonella species and two of its serovars ( $S$. enterica serovar Enteritidis and S. enterica serovar Typhimurium) in five different vegetables (cabbages, lettuces, tomatoes, carrots and cucumbers) collected from three hypermarkets and a wet market in Kampar, Perak. The microbial level of Salmonella in these vegetables was compared using the most probable number-multiplex polymerase chain reaction (MPN-mPCR) method.

\section{Materials and methods}

\subsection{Sample collection}

A total of 40 cabbages (Brassica oleracea var. capitata), 20 lettuces such as iceberg lettuce (L. sativa var. capitata), leafy lettuce ( $L$. sativa var. crispa), butterhead lettuce (L. sativa var. capitata) and romaine lettuce (L. sativa var. longifolia), 40 tomatoes (Solanum lycopersicum), 40 carrots (Daucus carota), and 40 cucumbers (Cucumis sativus) were randomly purchased from the hypermarket $\mathrm{A}, \mathrm{B}$ and $\mathrm{C}$ and a wet market in Kampar Perak, Malaysia over a period of 13 months (January 2018 to January 2019). The samples were collected and kept in a sterile polyethylene bag before delivered to the laboratory for further analysis on the same day.

\subsection{Detection and quantification of Salmonella by MPN- mPCR method}

A $10 \mathrm{~g}$ of freshly cut vegetables were weighed aseptically and transferred into a sterile stomacher bag (Interscience, Singapore). A $90 \mathrm{~mL}$ of sterile Buffered Peptone Water (BPW) (Merck, Germany) was added to the bag and pummelled for $60 \mathrm{~s}$ using BagMixer ${ }^{\circledR} 400$ stomacher machine (Interscience, France). The homogenized suspension was diluted to 100 and 1000 folds. Then, the 3-tube MPN method was carried out by transferring $1 \mathrm{~mL}$ from each dilution into three replicate tubes and incubated at $37^{\circ} \mathrm{C}$ for $4 \mathrm{hrs}$. After preenrichment, each of the suspensions was added to $10 \mathrm{~mL}$ of Rappaport-Vassiliadis-Soya (RVS) broth (Merck, Germany), followed by incubation at $37^{\circ} \mathrm{C}$ for $20 \mathrm{hrs}$ under aerobic condition (Pui et al., 2011; Najwa et al., 2015; Thung et al., 2018). The turbid MPN tubes were plated on Xylose Lysine Deoxycholate (XLD) agar (Oxoid Ltd, UK) and DNA was extracted before multiplex PCR (mPCR) was performed. The microbial load in each sample was quantified by referring to the MPN Table of Bacterial Analytical Manual (BAM) from the US FDA (Sutton, 2010).

\subsubsection{DNA extraction}

Boiled-cell DNA extraction method (Kuan et al., 2017) was used to extract the bacterial DNA. Briefly, 1 $\mathrm{mL}$ of broth culture from MPN tube was centrifuged at $15,000 \times g$ for 3 mins. The pelleted cells were resuspended in $200 \mu \mathrm{L}$ of Tris-EDTA buffer. The mixture was vortex and boiled for 10 mins. The solution was cooled immediately at $-20^{\circ} \mathrm{C}$ for 10 mins before it was centrifuged at $15,000 \times g$ for 3 mins. The supernatant was used as the DNA template for multiplex polymerase 
chain reaction (mPCR).

\subsubsection{Multiplex PCR (mPCR)}

The first primer pairs of ST11 (5'-GCC AAC CAT TGC TAA ATT GGC GCA-3') and ST15 (5'-GGT AGA AAT TCC CAG CGG GTA CTG G-3') was used to amplify the endonuclease gene at the size of $429 \mathrm{bp}$ for Salmonella spp. and the second primer pairs of ENTF (5'-TGT GTT TTA TCT GAT GCA AGA GG-3') and ENTR (5'-TGA ACT ACG TTC GTT CTT CTG G-3') was used to amplify the $s d f I$ gene which encodes for the transcriptional regulator on $S$. enterica serovar Enteritidis at $304 \mathrm{bp}$. The final set of primer pairs, Fli15 (5'-CGG TGT TGC CCA GGT TGG TAA T-3') and Typ04 (5'-ACT GGT AAA GAT GGC T-3') was used to detect the presence of $S$. enterica serovar Typhimurium by targeting the $f l i C$ gene which encodes for the flagellin protein at the amplicon size of $620 \mathrm{bp}$ (Kuan et al., 2017).

\section{Results}

\subsection{PCR amplification of Salmonella spp., Salmonella} enterica serovar Enteritidis and Salmonella enterica serovar Typhimurium in vegetables

The positive amplification of the three target genes specific to Salmonella spp., $S$. enterica serovar Enteritidis and $S$. enterica serovar Typhimurium produced products of $429 \mathrm{bp}, 304 \mathrm{bp}$ and $620 \mathrm{bp}$, respectively (Figure 1).

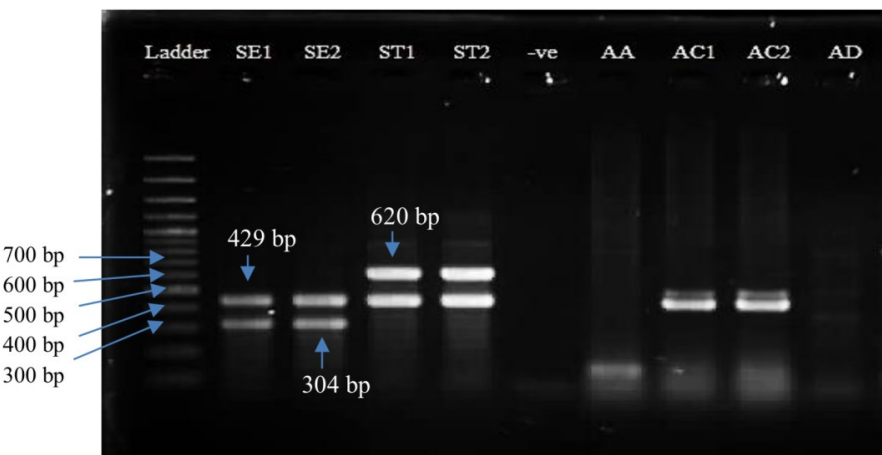

Figure 1. Representative amplification of $429 \mathrm{bp}$ segment of random sequence, $304 \mathrm{bp}$ segment of $S d f l$ gene and $620 \mathrm{bp}$ segment of fliC gene for the identification of Salmonella spp., S. enterica serovar Enteritidis and S. enterica serovar Typhimurium, respectively. Lane Ladder: 100 bp DNA ladder (Vivantis Technologies, USA). Lane SE1 and SE2: positive controls of $S$. enterica serovar Enteritidis with PCR amplicons specific to Salmonella spp. at $429 \mathrm{bp}$ and $S$. enterica serovar Enteritidis at 304 bp. Lane ST1 and ST2: positive controls of $S$. enterica serovar Typhimurium with PCR amplicons specific to Salmonella spp. at 429 bp and $S$. enterica serovar Typhimurium at 620 bp. Lane -ve: negative control. Lane AA and AD: negative samples. Lane $\mathrm{AC} 1$ and AC2: positive samples with PCR amplicon specific to Salmonella spp. at 429 bp.
3.2 Prevalence of Salmonella spp., Salmonella enterica serovar Enteritidis and Salmonella enterica serovar Typhimurium in vegetables

The prevalence of Salmonella spp., S. enterica serovar Enteritidis and $S$. enterica serovar Typhimurium in vegetables from the hypermarkets and wet market are tabulated in Table 1. Out of the five different types of vegetable samples tested, only cabbages and cucumbers were found to be positive to Salmonella spp. with the prevalence of $2.5 \%$ (one positive sample out of 40 samples) and $12.5 \%$ (five positive samples out of 40 samples), respectively. Besides, the total prevalence of $S$. enterica serovar Typhimurium in cucumbers purchased from the wet market and the hypermarkets was $10.0 \%$ (four positive samples out of 40 samples). The contamination rates of Salmonella spp. and S. enterica serovar Typhimurium was found to be slightly higher in the samples collected from the wet market than those from the hypermarkets. However, S. enterica serovar Enteritidis was absent in all the vegetable samples analysed.

\subsection{Microbiological load of Salmonella in vegetables}

In this study, Salmonella spp. was found to be the most prevalent in cucumber with the maximum concentration of $>1,100 \mathrm{MPN} / \mathrm{g}$, followed by cabbage with the maximum concentration of $15.0 \mathrm{MPN} / \mathrm{g}$ (Table 2). Among five different types of vegetables, cucumber was found to be an important reservoir for Salmonella, particularly $S$. enterica serovar Typhimurium with the highest concentration of $23.0 \mathrm{MPN} / \mathrm{g}$ and $>1,100 \mathrm{MPN} / \mathrm{g}$ were detected in cucumbers that were purchased from wet market and hypermarkets, respectively.

\section{Discussion}

In this study, the prevalence of Salmonella spp. and $S$. enterica serovar Typhimurium was found to be higher in the wet market than the hypermarkets. Nevertheless, both retail markets possess the risk of selling Salmonella contaminated vegetables. Hypermarkets are one-stop grocery stores, selling a variety of goods. The goods are organized systematically, and similar goods are placed together in different zones to minimize crosscontamination. It is always perceived to be clean and tidy. The centralised cooling facilities at the hypermarkets are built to maintain their inner temperature and humidity so that the quality of the goods, especially food items can be maintained (Castillo, 2010). However, the quality of vegetables and fruits may sometimes be affected due to late delivery by suppliers. Besides, Najwa et al. (2015) found that vegetables in hypermarkets are displayed for up to a week and hence have a longer holding time compared to wet markets. 
Table 1. Prevalence of Salmonella spp., S. enterica serovar Enteritidis and S. enterica serovar Typhimurium in fresh vegetables purchased from the hypermarkets and the wet market in Kampar, Perak

\begin{tabular}{|c|c|c|c|c|c|c|c|c|}
\hline \multirow[b]{3}{*}{ Vegetables } & \multicolumn{4}{|c|}{ Hypermarkets } & \multicolumn{4}{|c|}{ Wet market } \\
\hline & \multicolumn{4}{|c|}{ No. of positive sample, n (\%) } & \multicolumn{4}{|c|}{ No. of positive sample, n (\%) } \\
\hline & $\begin{array}{l}\text { Number of } \\
\text { samples (n) }\end{array}$ & $\begin{array}{c}\text { Salmonella } \\
\text { spp. }\end{array}$ & $\begin{array}{l}\text { S. enterica } \\
\text { serovar } \\
\text { Enteritidis }\end{array}$ & $\begin{array}{c}\text { S. enterica } \\
\text { serovar } \\
\text { Typhimurium }\end{array}$ & $\begin{array}{l}\text { Number of } \\
\text { samples (n) }\end{array}$ & $\begin{array}{l}\text { Salmonella } \\
\text { spp. }\end{array}$ & $\begin{array}{c}\text { S. enterica } \\
\text { serovar } \\
\text { Enteritidis }\end{array}$ & $\begin{array}{c}\text { S. enterica } \\
\text { serovar } \\
\text { Typhimurium }\end{array}$ \\
\hline Cabbage & 30 & $1(3.3 \%)$ & $0(0.0 \%)$ & $0(0.0 \%)$ & 10 & $0(0.0 \%)$ & $0(0.0 \%)$ & $0(0.0 \%)$ \\
\hline Tomato & 30 & $0(0.0 \%)$ & $0(0.0 \%)$ & $0(0.0 \%)$ & 10 & $0(0.0 \%)$ & $0(0.0 \%)$ & $0(0.0 \%)$ \\
\hline Lettuce & 14 & $0(0.0 \%)$ & $0(0.0 \%)$ & $0(0.0 \%)$ & 6 & $0(0.0 \%)$ & $0(0.0 \%)$ & $0(0.0 \%)$ \\
\hline Carrot & 30 & $0(0.0 \%)$ & $0(0.0 \%)$ & $0(0.0 \%)$ & 10 & $0(0.0 \%)$ & $0(0.0 \%)$ & $0(0.0 \%)$ \\
\hline Cucumber & 30 & $3(10.0 \%)$ & $0(0.0 \%)$ & $2(6.7 \%)$ & 10 & $2(20.0 \%)$ & $0(0.0 \%)$ & $2(20.0 \%)$ \\
\hline Total & 134 & $4(3.0 \%)$ & $0(0.0 \%)$ & $2(1.5 \%)$ & 46 & $2(4.4 \%)$ & $0(0.0 \%)$ & $2(4.4 \%)$ \\
\hline
\end{tabular}

Table 2. Microbial load of Salmonella spp., S. enterica serovar Enteritidis and S. enterica serovar Typhimurium (MPN/g) in fresh vegetables purchased from hypermarkets and wet market in Kampar, Perak

\begin{tabular}{|c|c|c|c|c|c|c|c|c|c|c|c|c|c|c|c|c|c|c|}
\hline \multirow{3}{*}{ Vegetables } & \multicolumn{9}{|c|}{ Hypermarkets } & \multicolumn{9}{|c|}{ Wet market } \\
\hline & \multicolumn{3}{|c|}{ Salmonella spp. } & \multicolumn{3}{|c|}{$\begin{array}{c}\text { S. enterica serovar } \\
\text { Enteritidis }\end{array}$} & \multicolumn{3}{|c|}{$\begin{array}{l}\text { S. enterica serovar } \\
\text { Typhimurium }\end{array}$} & \multicolumn{3}{|c|}{ Salmonella spp. } & \multicolumn{3}{|c|}{$\begin{array}{c}\text { S. enterica serovar } \\
\text { Enteritidis }\end{array}$} & \multicolumn{3}{|c|}{$\begin{array}{l}\text { S. enterica serovar } \\
\text { Typhimurium }\end{array}$} \\
\hline & Min & & $\Delta$ & Tin & C & IVIax & Min & Med & 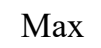 & & & & $\mathrm{M}$ & & Max & Min & & viad \\
\hline & 3.0 & .0 & & $<3.0$ & & $<3.0$ & $<3.0$ & & $<3.0$ & $<3$ & & J & $<3.0$ & & $<3.0$ & $<3$ & & $<3.0$ \\
\hline 011 & $<3.0$ & .0 & $<3.0$ & $<3.0$ & U & $<3.0$ & $<3.0$ & $<3.0$ & $<3.0$ & $<3.0$ & $<30$ & $<3.0$ & $<3$ & $<3.0$ & $<3$ & $<$ & 0 & $<3.0$ \\
\hline Let & $<3.0$ & $<3.0$ & $<3.0$ & $<3.0$ & $<3.0$ & $<3.0$ & $<3.0$ & 3 & $<3.0$ & $<3.0$ & $<$ & $<3.0$ & $<3.0$ & $<$ & $<3.0$ & $<3.0$ & .0 & $<3.0$ \\
\hline Car & $<3.0$ & $<3.0$ & $<3.0$ & $<3.0$ & $<3.0$ & $<3.0$ & $<3.0$ & $<3.0$ & $<3.0$ & $<3.0$ & $<3.0$ & $<3.0$ & $<3.0$ & $<3.0$ & $<3.0$ & $<3.0$ & $<3.0$ & $<3.0$ \\
\hline Cucumber & $<3.0$ & $<3.0$ & $>1100$ & $<3.0$ & $<3.0$ & $<3.0$ & $<3.0$ & $<3.0$ & $>1100$ & $<3.0$ & $<3.0$ & 23 & $<3.0$ & $<3.0$ & $<3.0$ & $<3.0$ & $<3.0$ & 23 \\
\hline
\end{tabular}

Min, minimum MPN/g value; Med, median MPN/g value; Max, maximum MPN/g value

This scenario has compromised the freshness of vegetables which leads to the growth of foodborne pathogens. This is supported by the findings in the present study that the microbial load of Salmonella spp. $(>1,100 \mathrm{MPN} / \mathrm{g})$ was higher in hypermarket. On the other hand, wet markets are often perceived as wet, filthy and smelly. They are not equipped with any cooling facilities. Consequently, this will also promote the growth of Salmonella.

On the contrary, Vital et al. (2014) found that the incidence of Salmonella contamination in the wet markets and the hypermarkets were similar (Vital et al., 2014). However, Najwa et al. (2015) reported that the prevalence of Salmonella spp., S. enterica serovar Enteritidis and $S$. enterica serovar Typhimurium in raw vegetables from hypermarkets were higher than those from the wet markets. Similarly, Loo et al. (2013) found that the prevalence and microbial load of other foodborne pathogen, Shiga toxin-producing Escherichia coli (STEC) in raw vegetables from hypermarkets was higher as compared to the wet markets.

The number of reported cases of Salmonella contamination in raw vegetables is very rare. This is supported by the observation of very low or the absence Salmonella in tomatoes, lettuces and carrots in this study. Food with no or low concentration of foodborne pathogens does not imply that they are safe for consumption, as other microbes can grow to a certain level to cause food poisoning under favourable conditions. Susceptible groups such as immunecompromised patients or pregnant women are easily infected by a sub dosage of foodborne pathogens. Other foodborne pathogens such as E. coli O104:H4, E. coli O157:H7, Cyclospora cayetanensis, Norovirus, Listeria monocytogenes, Staphylococcus aureus and Klebsiella pneumoniae had also been reported in raw vegetables (Puspanadan et al., 2012; Chang et al., 2013; Loo et al., 2013; Kuan et al., 2017; CDC, 2019a). Therefore, active surveillance must be conducted routinely to ensure that these raw vegetables are safe for consumption.

In the present study, the prevalence of Salmonella in cabbages was found to be much lower compared to the results of Nillian et al. (2011), where the contamination rates of Salmonella spp., S. enterica serovar Enteritidis and $S$. enterica serovar Typhimurium were $28.0 \%$, $24.0 \%$ and $16.0 \%$, respectively. However, in an earlier report by Kuan et al. (2017), Salmonella spp., S. enterica serovar Enteritidis and S. enterica serovar Typhimurium were not detected in cabbages from Kuala Lumpur, Selangor and Putrajaya. Such differences in the detection of foodborne pathogens are not uncommon as differences arise during pre- and post-harvest handling, especially in hygienic and agricultural practices (Jung et al., 2014; Kuan et al., 2017). 
Throughout the sampling period, it was observed that cucumbers in the retail markets were poorly sanitized as dirt and soil could be seen adhering on the cucumbers. The presence of dirt or soil might pose an increased risk of contamination by Salmonella. This might be the reason for the highest prevalence of Salmonella $(12.5 \%)$ in cucumbers among the other vegetables in this study. A study has been reported that Salmonella can survive in the soil for as long as 231 days (Islam et al., 2004). Bacteria present in the non-hygienic or contaminated display sites which initiated its biofilms formation on the vegetable surfaces.

Interestingly, Salmonella was not found in tomatoes, lettuces and carrots in the present study. These findings suggested that tomato, lettuce and carrot might not be a good vehicle for the Salmonella contamination. However, contrary results were reported by Kuan et al. (2017), with $7.7 \%$ of carrot sample was contaminated with $S$. enterica serovar Enteritidis. Similarly, Sabbithi et al. (2014) reported that $58.5 \%$ of the carrots used in the salads sold as street food in Hyderabad, India, were contaminated with Salmonella. In Dhanbad, India, 3.3\% of the carrots collected from the local market were contaminated with Salmonella (Mritunjay and Kumar, 2017).

Apart from Salmonella, other microbial pathogens such as E. coli, L. monocytogenes, $S$. aureus, may grow in cabbages (Mritunjay and Kumar, 2017). According to the studies done by Prazak et al. (2002) and Kuan et al. (2017), $4.7 \%$ and $18.2 \%$ of cabbages were contaminated by $L$. monocytogenes in Texas, United States and Selangor, Malaysia respectively. Outbreaks of food poisoning associated with contaminated cabbage had been reported (Solomon et al., 1990; Dunn et al., 1995; CDC, 2018). C. botulinum, Shigella flexneri, E. coli O157:H7, E. coli O169:H49, E. coli $\mathrm{O} 111$ and S. aureus were detected in these outbreaks.

Although the prevalence of Salmonella was low in this study, several sources that may cause raw vegetables being contaminated with Salmonella or other foodborne pathogens along the food supply chain including preharvesting, harvesting, post-harvesting, transportation and processing. The environment, animal and human may serve as the diverse risk factors of fresh produce contamination (Antwi-Agyei et al., 2015). Soil is one of the sources that may cause cross-contamination during pre-harvesting as foodborne pathogens may transfer to vegetables from contaminated soil. Therefore, vegetables that are close contact with the soil during planting have higher contamination risk (Nillian et al., 2011; Loo et al., 2013). The contaminated irrigation water, animal manure, untreated sewage sludge, insects, pests and the access of domestic or wild animals in the farm will cause the soil and the crops being contaminated with the pathogens. Besides that, uneducated and untrained workers with poor handling practices during harvesting and post-harvesting could lead to cross-contamination on the raw vegetables. Apart from that, the non-hygienic workplaces and surrounding environments with poor sanitation play a major role in microbial contamination. This is especially true for raw vegetable display areas which are seldom or improperly sanitized and cleaned at the retail markets (Loo et al., 2013; Najwa et al., 2015).

Therefore, good agricultural practices (GAP), good manufacturing practices (GMP) as well as Hazard Analysis and Critical Control Points (HACCP) should be incorporated in the food chain in order to reduce and prevent the risks of contamination of fresh produce from farm to plate (Antwi-Agyei et al., 2015). Nina (2019) has recommended consumers to select non-bruised vegetables; vegetables separated from animal origin foods such as meat, poultry and seafood; properly washed vegetables; and properly stored vegetables at an appropriate temperature. Susceptible groups such as pregnant women, elderly or individual who have weakened immune system should avoid consuming raw vegetables and lightly cooked food (Nina, 2019).

According to the guidelines of the Institute of Medicine and National Research Council Committee (2003) as well as the Centre for Food Safety (2014) in Ireland and Hong Kong, respectively, Salmonella spp. shall not be detected at $25 \mathrm{~g}$ of food that is ready to be eaten because as few as one organism of Salmonella spp. could result in non-typhoidal salmonellosis and less than $10^{3}$ organisms could cause typhoid fever. However, this standard varies in different countries (Antwi-Agyei et al., 2015). In Malaysia, there is no clear statement about the acceptable level in the Malaysia Food Act 1983 and Food Regulations 1985.

In this study, MPN-mPCR was chosen for its rapid and high accuracy in the detection of species-specific genes of foodborne pathogens. The multiplex PCR was used to detect the presence of Salmonella by amplifying a specific short target sequence of Salmonella DNA. The target sequences chosen are endonuclease gene of Salmonella spp., SdfI gene of S. enterica serovar Enteritidis and $\mathrm{fliC}$ gene of $S$. enterica serovar Typhimurium. However, PCR-based methods are limited to qualitative determination. It amplifies DNAs of targeted sequence present in the samples including the viable but non-culturable cells (VBNC) and dead pathogens in food samples (Saroj et al., 2008). This might create false-positive results. According to Borowsky, Schmidt and Cardoso (2007), the quantity of 
microorganisms present in the food sample is critical for the microbiological risk assessment (Borowsky et al., 2007). Therefore, to overcome the limitation of mPCR, MPN method is often applied to accurately quantify the pathogens. Over the past 10 years, there were numerous studies utilising MPN-mPCR assay to detect and enumerate the foodborne pathogens in food samples (Nillian et al., 2011; Pui et al., 2011; Puspanadan et al., 2012; Chang et al., 2013; Kuan et al., 2013; Loo et al., 2013; Najwa et al., 2015; Kuan et al., 2017; Othman et al., 2018; Thung et al., 2018). MPN-mPCR is able to produce results within two days compares to the conventional biochemical method which takes up from 7 -10 days (Pui et al., 2011).

\section{Conclusion}

Overall, Salmonella spp., S. enterica serovar Enteritidis and $S$. enterica serovar Typhimurium were not detected in tomatoes, carrots and lettuces. However, low prevalence of Salmonella spp. was detected in cabbage and cucumber. The detection of Salmonella spp. in cabbage and cucumber raises the concern on the hygienic and safety of the consumption of not only cabbages and cucumbers, but in other raw vegetables. Various types of foodborne pathogens may grow and cause a threat to the consumer's health. As such, susceptible groups such as elderly, immunocompromised patients and pregnant women should avoid consuming raw vegetables to reduce the risk of bacterial infection. The results obtained from this study might be useful as baseline information for the risk assessment on the microbiological quality of vegetables since there is an increasing number of Malaysians eating raw or minimally processed vegetables daily.

\section{Conflict of Interest}

The authors declare no conflict of interest.

\section{Acknowledgement}

This study was supported by the Final Year Project funding of Faculty of Science, Universiti Tunku Abdul Rahman, and in part, by the Fundamental Research Grant Scheme (FRGS) of the Ministry of Higher Education (MOHE), Malaysia (FRGS/1/2019/SKK06/UTAR/03/2).

\section{References}

Antwi-Agyei, P., Cairncross, S., Peasey, A., Price, V., Bruce, J., Baker, K., Moe, C., Ampofo, J., Armah, G. and Ensink, J. (2015). A farm to fork risk assessment for the use of wastewater in agriculture in Accra, Ghana. PLoS ONE, 10(11), 1-19. https:// doi.org/10.1371/journal.pone.0142346
Bordini, M.E.B., Asturiano Ristori, C., Jakabi, M. and Gelli, D.S. (2007). Incidence, internalization and behavior of Salmonella in mangoes, var. Tommy Atkins. Food Control, 18(8), 1002-1007. https:// doi.org/10.1016/j.foodcont.2006.06.003

Borowsky, L.M., Cardoso, M. and Alegre, P. (2007). Estimation of Most Probable Number of Salmonella. Brazilian Journal of Microbiology, 38, 544-546. https://doi.org/10.1590/S1517-83822007000300030

Castillo, L. (2010). Wet Market or Supermarket? Retrieved on May 18, 2019 from The Philippine Star Website: https://www.philstar.com/other-sections/ starweek-magazine/2010/03/28/561527/wet-marketor-supermarket

CDC (Centers for Disease Control and Prevention). (2006). Multistate Outbreak of Salmonella Typhimurium Infections Linked to Tomatoes (Final Update). Retrieved on May 18, 2019 from CDC Website: https://www.cdc.gov/salmonella/2006/ tomatoes-11-2006.html

CDC (Centers for Disease Control and Prevention). (2018). National Outbreak Reporting System (NORS). Retrieved on May 8, 2019 from CDC Website: $\quad$ https://www.cdc.gov/nors/data/usingnors.html

CDC (Centers for Disease Control and Prevention). (2019a). Food Poisoning Symptoms. Retrieved on May 8, 2019 from CDC Website: https:// www.cdc.gov/foodsafety/symptoms.html

CDC (Centers for Disease Control and Prevention). (2019b). Salmonella. Retrieved on May 3, 2019 from CDC Website: https://www.cdc.gov/salmonella/

Centre for Food Safety. (2014). Microbiological Guidelines for Food. Retrieved on October 18, 2018 from Centre for Food Safety Website: <https:// www.cfs.gov.hk/english/food_leg/files/

food leg Microbiolo gical_Guidelines_for_Food_e.pdf>

Chang, W.S., Afsah-Hejri, L., Rukayadi, Y., Khatib, A., Lye, Y.L., Loo, Y.Y., Mohd Shahril, N., Puspanadan, S., Kuan, C.H., Goh, S.G., John, Y.H.T., Nakaguchi, Y., Nishibuchi, M. and Son, R. (2013). Quantification of Escherichia coli O157:H7 in organic vegetables and chickens. International Food Research Journal, 20(2), 1023-1029.

Dunn, R.A., Hall, W.N., Altamirano, J.V., Dietrich, S.E., Robinson-Dunn, B. and Johnson, D.R. (1995). Outbreak of Shigella flexneri linked to salad prepared at a central commissary in Michigan. Public Health Reports, 110, 580-586.

Hendriksen, R.S., Vieira, A.R., Karlsmose, S., Lo Fo Wong, D.M., Jensen, A.B., Wegener, H.C. and 
Aarestrup, F.M. (2011). Global monitoring of Salmonella serovar distribution from the World Health Organization Global Foodborne Infections Network Country Data Bank: results of quality assured laboratories from 2001 to 2007. Foodborne Pathogens and Disease, 8(8), 887-900. https:// doi.org/10.1089/fpd.2010.0787

Institute of Medicine and National Research Council Committee. (2003). Scientific Criteria to Ensure Safe Food. Washington, D.C., USA: National Academies Press.

Islam, M., Morgan, J., Doyle, M.P., Phatak, S.C., Millner, P. and Jiang, X. (2004). Persistence of Salmonella enterica serovar Typhimurium on lettuce and parsley and in soils on which they were grown in fields treated with contaminated manure composts or irrigation water. Foodborne Pathogens and Disease, 1(1), 27-35. https:// doi.org/10.1089/153531404772914437

Jung, Y., Jang, H. and Matthews, K.R. (2014). Effect of the food production chain from farm practices to vegetable processing on outbreak incidence. Microbial Biotechnology, 7(6), 517-527. https:// doi.org/10.1111/1751-7915.12178

Kuan, C.H., Wong, W.C., Pui, C.F., Tang, J.Y.H., Nishibuchi, M., Mahyudin, N.A. and Son, R. (2013). Prevalence and quantification of Listeria monocytogenes in beef offal at retail level in Selangor, Malaysia. Brazilian Journal of Microbiology, 44(4), 1169-1172. https:// doi.org/10.1590/S1517-83822014005000002

Kuan, C.H., Lim, L.W.K., Ting, T.W., Rukayadi, Y., Ahmad, S.H., Wan Mohamed Radzi, C.W.J., Thung, T.Y., Ramzi, O.B., Chang, W.S., Loo, Y.Y., Kuan, C.S., Yeo, S.K. and Radu, S. (2017). Comparison of the microbiological quality and safety between conventional and organic vegetables sold in Malaysia. Frontiers in Microbiology, 8, 1433. https://doi.org/10.3389/fmicb.2017.01433

Loo, Y.Y., Puspanadan, S., Goh, S.G., Kuan, C.H., Chang, W.S., Lye, Y.L., John, Y.H.T, Rukayadi, Y., Yoshitsugu, N., Nishibuchi, M. and Son, R. (2013). Quantitative detection and characterization of Shiga toxin-producing Escherichia coli $\mathrm{O} 157$ and nonO157 in raw vegetables by MPN-PCR in Malaysia. International Food Research Journal, 20(6), 33133317.

Mritunjay, S.K. and Kumar, V. (2017). A study on prevalence of microbial contamination on the surface of raw salad vegetables. 3 Biotech, 7(1), 1-9. https:// doi.org/10.1007/s13205-016-0585-5

Najwa, M.S., Rukayadi, Y., Ubong, A., Loo, Y.Y., Chang, W.S., Lye, Y.L., Thung, T.Y, Aimi, S.A.,
Malcolm, T.T.H, Goh, S.G., Kuan, C.H., Yoshitsugu, N., Nishibuchi, M. and Son, R. (2015). Quantification and antibiotic susceptibility of Salmonella spp., Salmonella Enteritidis and Salmonella Typhimurium in raw vegetables (ulam). International Food Research Journal, 22(5), 17611769.

Nillian, E., Chai, L.C., Pui, C.F., Tunung, R., Ubong, A., Tuan, Z.T.C., Son, R. and Mitsuaki, N. (2011). Simultaneous detection of Salmonella spp., Salmonella Enteritidis and Salmonella Typhimurium in raw salad vegetables and vegetarian burger patties. Food and Nutrition Sciences, 2(10), 10771081. https://doi.org/10.4236/fns.2011.210144

Nina, K. (2019). What are The Dangers of Eating Raw Vegetables? Retrieved on May 8, 2019 from Livestrong.com Website: https:// www.livestrong.com/article/331319-what-are-thedangers-of-eating-raw-vegetables/

Nurul Izzah, A., Aminah, A., Md Pauzi, A., Lee, Y.H., Wan Rozita, W.M. and Siti Fatimah, D. (2012). Patterns of fruits and vegetable consumption among adults of different ethnics in Selangor, Malaysia. International Food Research Journal, 19(3), 10951107.

Othman, B.R., Kuan, C.H., Abdulkarim Sabo, M., Cheah, Y.K., Tan, C.W., New, C.Y., Thung, T.Y., Chang, W.S., Loo, Y.Y., Nakaguchi, Y., Nishibuchi, M. and Son, R. (2018). Occurrence of methicillinresistant Staphylococcus aureus in raw shellfish at retail markets in Malaysia and antibacterial efficacies of black seed (Nigella sativa) oil against MRSA. Food Control, 90, 324-331. https:// doi.org/10.1016/j.foodcont.2018.02.045

Prazak, A.M., Murano, E.A., Mercado, I. and Acuff, G.R. (2002). Prevalence of Listeria monocytogenes during production and postharvest processing of cabbage. Journal of Food Protection, 65(11), 17281734. https://doi.org/10.4315/0362-028X-65.11.1728

Pui, C.F., Wong, W.C., Chai, L.C., Nillian, E., Ghazali, F.M., Cheah, Y.K., Nakaguchi, Y., Nishibuchi, M. and Radu, S. (2011). Simultaneous detection of Salmonella spp., Salmonella Typhi and Salmonella Typhimurium in sliced fruits using multiplex PCR. Food Control, 22(2), 337-342. https:// doi.org/10.4315/0362-028X-65.11.1728

Puspanadan, S., Afsah-Hejri, L., Loo, Y.Y, Nillian, E., Kuan, C.H., Goh, S.G., Chang, W.S., Lye, Y.L., John, Y.H.T., Rukayadi, Y., Yoshitsugu, N., Nishibuchi, M. and Son, R. (2012). Detection of Klebsiella pneumoniae in raw vegetables using Most Probable Number-Polymerase Chain Reaction (MPN -PCR). International Food Research Journal, 19(4), 
1757-1762.

Sabbithi, A., Kumar, R.N., Kashinath, L., Bhaskar, V. and Rao, V.S. (2014). Microbiological quality of salads served along with street foods of Hyderabad, India. International Journal of Microbiology, 2014, 1-6. https://doi.org/10.1155/2014/932191

Saroj, S.D., Shashidhar, R., Karani, M. and Bandekar, J.R. (2008). Rapid, sensitive, and validated method for detection of Salmonella in food by an enrichment broth culture - Nested PCR combination assay. Molecular and Cellular Probes, 22(3), 201-206. https://doi.org/10.1016/j.mcp.2008.02.002

Solomon, H.M., Kautter, D.A., Lilly, T. and Rhodehamel, E.J. (1990). Outgrowth of Clostridium botulinum in shredded cabbage at room temperature under a modified atmosphere. Journal of Food and Protection, 53(10), 831-833. https:// doi.org/10.4315/0362-028X-53.10.831

Sutton, S. (2010). The most probable number method and its uses in enumeration, qualification, and validation. Journal of Validation Technology, 16(3), 35-38.

Suzanne. (2016). Salmonella Outbreak Rises to 62 Cases in Victoria from Contaminated Loose-Leaf Lettuce. Retrieved on August 17, 2019 from The Age Website: https://www.theage.com.au/national/ victoria/salmonella-outbreak-rises-to-62-cases-invictoria-from-contaminated-looseleaf-lettuce20160208-gmod3r.html

Thung, T.Y., Radu, S., Mahyudin, N.A., Rukayadi, Y., Zakaria, Z., Mazlan, N., Tan, B.H., Lee, E., Yeoh, S.L., Chin, Y.Z., Tan, C.W., Kuan, C.H., Basri, D.F. and Radzi, C.W.J.W.M., (2018). Prevalence, virulence genes and antimicrobial resistance profiles of Salmonella serovars from retail beef in Selangor, Malaysia. Frontiers in Microbiology, 8, 1-8. https:// doi.org/10.3389/fmicb.2017.02697

Tunung, R., Chai, L.C., Usha, M.R., Lesley, M.B., Cheah, Y.K., Patrick, G.B., Farinazleen, M.G., Fatimah, A.B., Malakar, P.K. and Son, R. (2007). Incidence and characterization of Salmonella species in street food and clinical samples. Journal of Food Safety, 27(4), 345-361. https://doi.org/10.1111/ j.1745-4565.2007.00089.x

Vital, P.G., Dimasuay, K.G.B., Widmer, K.W. and Rivera, W.L. (2014). Microbiological quality of fresh produce from open air markets and supermarkets in the Philippines. Scientific World Journal, 2014, $21-7 . \quad$ https:// doi.org/10.1155/2014/219534

Von Haaren, H. (2004). Fast Food Lettuce Blamed for Salmonella Outbreak. Retrieved on August 17, 2019 from The Times Website: https:// www.thetimes.co.uk/article/fast-food-lettuce-blamed -for-salmonella-outbreak-c8xn251k90m.

World Health Organization (WHO). (2018). Salmonella (Non-Typhoidal). Retrieved on August 17, 2019 from WHO Website: https://www.who.int/newsroom/fact-sheets/detail/salmonella-(non-typhoidal) www.cdc.gov/foodsafety/symptoms.html 